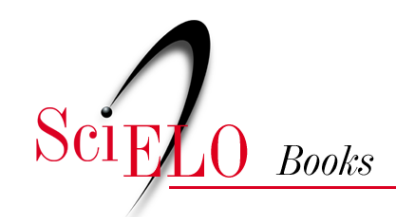

\title{
Homossexualidade e nação nos diários de Tulio Carella
}

\author{
Leandro Soares da Silva
}

\section{SciELO Books / SciELO Livros / SciELO Libros}

SILVA, LS. Homossexualidade e nação nos diários de Tulio Carella. In: MITIDIERI, AL., and CAMARGO, FP., orgs. Literatura, homoerotismo e expressões homoculturais [online]. Ilhéus, BA: Editus, 2015, pp. 117-138. ISBN 978-85-7455-442-6. Available from SciELO Books <http://books.scielo.org>.

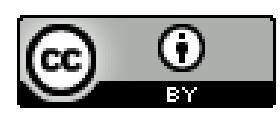

All the contents of this work, except where otherwise noted, is licensed under a Creative Commons Attribution $\underline{4.0 \text { International license. }}$

Todo o conteúdo deste trabalho, exceto quando houver ressalva, é publicado sob a licença Creative Commons Atribição 4.0.

Todo el contenido de esta obra, excepto donde se indique lo contrario, está bajo licencia de la licencia Creative Commons Reconocimento 4.0. 


\title{
HOMOSSEXUALIDADE E NAÇÃO NOS DIÁRIOS DE TULIO CARELLA
}

\author{
Leandro Soares da Silva
}

A história daqueles que, oriundos de outras terras, chegaram ao Brasil e não resistiram ao registro, é uma copiosa história de estranhamento e fascínio. Seus relatos serviram de espelho para que a própria ideia de brasilidade fosse erigida, ou confirmada, e mesmo quando o exótico e o primitivo se impõem na visão desses estrangeiros, é como discurso sobre a nação brasileira que se impõem. O aparato discursivo que descreve, nomeia e controla a identidade nacional foi apoderado pelos nossos escritores desde o romantismo, onde funcionou como projeto literário, e continua atuante até hoje. De estranhos e estrangeiros que sobre esta parte do continente dispensaram algumas páginas, sejam elas de diários, cartas, romances, poemas ou relatórios governamentais, pouco conhecidas são as escritas por um professor e autor argentino que viveu no nordeste brasileiro.

1 Doutorando em Teoria Literária e Literatura Comparada, pela Universidade Federal de Minas Gerais. Professor Auxiliar de Literatura Brasileira e Portuguesa, na Universidade do Estado da Bahia. E-mail: <leocapim@gmail.com>. 
Tulio Carella é esse escritor. Viveu no Recife entre 1960 e 1962, convidado para ministrar aulas no curso de teatro, e saiu do país porque sua conduta levou à desconfiança de que estaria envolvido com contrabando. Provavelmente, naquela época, um estrangeiro frequentador assíduo do porto seria visto com muito maior receio que hoje. O que a policia descobriu, depois de torturá-lo e revistar seu apartamento, foi muito mais inesperado. Nos diários encontrados pela polícia, consta a abundante história de um homem fascinado pelo Recife e pelo Brasil, mas muito mais dedicado a descobrir o segredo por trás dos corpos negros dos homens - muitos homens - com quem fazia sexo. De volta à Argentina, Carella retrabalhou o texto do diário, transformando -o numa espécie de roman à clef. Publicou-os no Brasil em 1968, sob o título de Orgia: diário primeiro, claro que pelo seu título, pelo menos, outro viria à luz. Esgotado, o livro só receberia outra edição, em 2011, sem que novos volumes surgissem e sem que o original em espanhol fosse encontrado. A história de Carella nunca foi publicada em seu país.

Edward Said (2007, p. 15), revendo seu Orientalismo, em 2003, defende que o conhecimento de outros povos se manifesta em duas modalidades de desejo: "o desejo de compreender por razões de coexistência e de alargamento de horizontes, e o desejo de conhecimento por razões de controle e dominação externa".

O desejo de Carella é, sobretudo, do primeiro tipo: é evidente seu medo de dissolver-se, 
como argentino, no país que o recebe, mas entende positivamente o contato com pessoas com hábitos, formas de convivência e histórias tão diversos dos seus. O seu não é um olhar que pressupõe a dominação, mas, em certo ponto da narrativa, o autor - sob o alter ego de Lucio Ginarte - deixa de lado as intenções de pensar a latinidade dos individuos de uma maneira, digamos, a aproximar a experiência nordestina da de Buenos Aires, para impor a si mesmo o papel de agente portador das graças iluministas.

Citado por Homi Bhabha, Partha Chatterjee aponta a dificuldade de um nacionalismo calcado numa imagem do Iluminismo porque este, "para afirmar sua soberania como ideal universal, necessita de um Outro; se pudesse de fato se efetivar no mundo real como o verdadeiramente universal, na verdade destruiria a si próprio" (1998, p. 201). O texto de Carella, nesse sentido, não se funda em defesa do nacional ou em comparações entre nacionalidades distintas amparadas nas grandes rubricas "América Latina" ou "sul-americano", como parecia intentar. O Iluminismo aparece no ideal civilizatório de alguém que se reconhece descendente e continuador de uma cultura letrada - e se é letrada, no contexto do nordeste brasileiro, em meados do século passado, é superior.

Os diários de Carella contam a história de um desejo que desconstrói basilarmente o discurso nacional na forma de uma contranarrativa da heterossexualidade. Deslocando seu enfoque da descrição do fascínio e estranhamento, 
que a nação brasileira lhe desperta, para a descrição obsessiva de encontros realizados com homens pobres, negros e mestiços do Recife, o narrador Ginarte/Carella deixa vago o espaço para se pensar sobre a nacionalidade a partir da categoria da sexualidade.

Este texto argumentará com base na necessidade de se pensar a nação a partir de discursos que permanecem atuando de modo subalterno na constituição do imaginário nacional, tanto no aspecto homoerótico da narrativa literária quanto no aspecto, que considero mais importante, de deslizamento do monolito essencialista da heterossexualidade. Como fonte simbólica, a heterossexualidade é uma estratégia de identificação cultural de um povo questionada pelos estudos gays e lésbicos, geralmente, a partir da contraparte narrativa que põe em evidência a experiência homossexual. Mas são relatos como os de Carella que possibilitam um questionamento a partir da própria norma hetero, sem a necessidade de se chamar a identidade gay para a arena do contraponto.

A ambivalência da "nação" como estratégia narrativa, afirma Homi Bhabha, é possibilitada pela

[...] força narrativa e psicológica que a nacionalidade apresenta na produção cultural e na projeção política [. E prossegue:] como aparato de poder simbólico, isto produz um deslizamento contínuo de categorias, como sexualidade, afiliação de classe, para- 
noia territorial ou 'diferença cultural' no ato de escrever a nação (1998, p. 200 - grifo do autor).

Situando-se na zona liminar desse deslocamento, tentarei discutir a narrativa da nação sob o signo da heterossexualidade, que considero frágil e erodida, sem debater sobre a diferenciação com base na experiência de sujeitos heterossexuais. Em outras palavras, o diário de Carella serve de base a uma argumentação mais panorâmica e conceitual sobre a (hetero) sexualidade, mesmo quando recorre a exemplos mais concretos de vivência pessoal.

A história do desejo contada por Tulio Carella, em seus diários, é a história de uma nação percebida por um estrangeiro como sexualizada, mas com uma natureza masculina que até se poderia compreender como a história de um desejo homossexual. Contudo ela revela este desejo duplamente inominado: não só por causa da natureza dos atos em que se realiza, mas também por não existir qualquer possibilidade de identidade gay definida pela escrita. O desejo sob o sol do Recife é da ordem de uma estrutura masculina e heterossexual, em que o sexo rotineiro e fortuito do protagonista não se confunde com uma ideia de individuo gay.

Ainda que reconheça - e rejeite - aqueles que considera óbvios homossexuais, não é nessa esfera que Carella/Ginarte põe sua própria pulsão, nem mesmo a da maioria dos seus parceiros. Estes, assim como ele, desbastam a 
selva escura de um desejo que é quase necessidade, que flui irresistivel pelas ruas e bares, que se impõe aos corpos, como a fome, a sede, o sono. O lugar desse desejo sem nome é o espaço público onde o pouco de mulheres que são vistas - como observa o narrador - é, na maioria, de reputação duvidosa; lugar, portanto, mais uma vez, masculino e estruturado sob as relações entre homens heterossexuais.

Nas inúmeras conquistas de Carella/Ginarte não se encontra nenhum homem que se reconheça ou exerça sua sexualidade sob o dominio de um signo que seja o do homossexual. Estas figuras, com o que elas representam em termos de identidade, comportamento e trânsito específicos, aparecem à margem das narrativas, como pegajosas, moles ou insistentes, literalmente no caminho que o autor percorre em busca de rapazes e homens casados, solteiros, inexperientes ou viciados - mas que não renunciaram à estrutura da norma heterossexual. De fato, é com iguais a si que Carella, casado há vários anos, prefere se relacionar.

Ainda que se proponha a pergunta "O que é um homossexual?", depois de seu primeiro encontro com um rapaz, o narrador a abandona abruptamente pela questão "O que é um negro?", repetida algumas vezes ao longo do livro. O desejo que escorre dos diários de Tulio Carella é pelos negros e mestiços em seu cromatismo variado, numa obsessão que revela uma atração pelo exótico, ainda que o texto tente se abster desse exotismo erótico.

Ele também chega a perceber a si mesmo 
como algo excêntrico e conclui que a atração que exerce sobre os recifenses se deve à sua condição de estrangeiro, com modos, aparência e mesmo roupas diferentes dos daquelas pessoas. Claro que esse estatuto se impõe nas suas relações sexuais, que ele metaforiza como encontros entre culturas distintas. Dadas as diferenças sociais e culturais entre o escritor argentino e seus parceiros, uma relação de força se desenha: embora desempenhe um papel sexual submisso, o narrador faz uma leitura diversa. Quando um parceiro o penetra, considera que para o negro "é preciso que entre nesse corpo pálido, alheio à sua terra, para comunicar-se com os deuses brancos que o habitam, mesmo que tenha de rasgá-lo e fazê-lo sangrar" (CARELLA, 2011, p. 121).

Carella não foge de uma visão exótica e sexualizada do país, como ele genuinamente parece evitar. Sua questão tão reiterada, "o que é um negro?", encontra a resposta no fascinio pelo corpo negro masculino: para o narrador, o pênis é o melhor que os negros têm para oferecer aos brancos e, mesmo durante os atos ("Ele pega no meu pênis e eu no dele - o que é um negro?"), a questão lhe retorna mesclada à própria resposta. Esta nação, de morenos, negros, sararás e mestiços, tem-lhe basicamente a oferecer nada além de seus corpos. A contraparte dessa equação é sua postura civilizatória. $\mathrm{Na}$ universidade, trabalha como professor de teatro, registra o gosto dos alunos por suas aulas, a inveja e depois a cópia de seus métodos por outros professores. Nas ruas, admira-se e se 
preocupa com "a falta de etiqueta dos negros, de alguns negros [...] procuro semear, orientar, inculcar alguma ideia que frutifique com o tempo" (CARELLA, 2011, p. 136).

Encanta-se com o olhar demorado de King Kong, seu amante mais destacado, sobre seus óculos e livros, entende que o rapaz se fascina com os símbolos de uma intelectualidade que não possui - descrito em detalhes, King Kong é um centauro, um touro, um ser gigantesco, puro músculo, possuidor de uma malícia previsível, e não mais do que isso.

Suas relações com esses homens todos que, além de negros, são sempre pobres, leva o narrador à conclusão de que, embora haja algum preconceito, não existe discriminação racial, de que as tensões raciais se equilibram no cotidiano. Sua chave de leitura para chegar a tal conclusão é a sexualidade: "O que me atrai no Recife é a atmosfera moral, ou melhor, imoral. Isto é a África com as vantagens do Ocidente" (CARELLA, 2011, p. 168).

É nesta atmosfera que o narrador perde suas ligações originárias, aproximando-se do novo espaço a partir de uma velha conhecida, a suposta sensualidade brasileira, que se revela através do exercício ilimitado da sexualidade. A perda da "origem", contudo, se dá pela plena realização de sua necessidade de sexo homossexual. Aos poucos, Buenos Aires se constitui apenas um lugar para o qual enviar cartas. Carella/Ginarte deixa-se dissolver em solo brasileiro, ainda que jamais abandone a referência de sua pátria, que 
aqui funciona como a civilização letrada que vem fundar, nesta "África ocidental", exíguos alicerces que, de fato, são apenas simbolos de uma superioridade precária: modos de etiqueta, leituras literárias, roupas e sapatos de outra qualidade.

Sua identidade nacional não é afetada, assim como sua identidade sexual. O que o afeta ao ponto de se transformar é a prática erótica, que, no Brasil, possui um contorno obsessivo. Ainda que tantos antes e depois de Carella tenham interpretado o Brasil pela via do sexo e da sensualidade, é sua vivência numa "nação de invertidos" que sugere um olhar para os discursos subterrâneos da nacionalidade. $\mathrm{O}$ foco exclusivo na sexualidade masculina é a grande novidade dessa interpretação, pois desloca a ênfase sobre a mulher brasileira e sua sexualidade quase promíscua, conforme o cânone, para corpos de homens negros, pobres, semialfabetizados.

O corpo negro masculino é o fetiche, não o da mulata. Pergunta-se o que é um negro porque a visão o aflige como um cilício, cuja recompensa à dor de ser penetrado equivale a uma experiência mística e a uma dose de iluminismo para o povo agreste. Nação de invertidos em sua acepção restrita: invertidos não por desejarem outros homens, mas invertidos porque representam, no privado, o contrário de sua atuação pública.

O subterrâneo recifense, descrito pelo autor argentino, é uma amostra local de uma experiência mais geral e, salvo por causa de relatos 
como o seu diário, oculta da norma que organiza não somente as relações entre homens e mulheres, mas também o discurso nacional. Caso se pense na construção da masculinidade do homem nordestino, a reiteração de seu caráter de macho e da tradição que obriga este homem a ser estereotipado como rude e brutalizado, o relato franco de seus diários é uma desconstrução irreparável dessa figura. A experiência de homens e mulheres gays presume a criação de espaços de sociabilidade, onde suas identidades possam ser vividas com algum controle e com algum sossego é fato antigo e cada vez mais consolidado. No Recife da década de 1960, para Carella, esses espaços são as ruas, os banheiros públicos, a orla da cidade. A frequência, nesses lugares, de homens casados ou heteros é equiparável à de homossexuais, facilmente reconheciveis pelos seus modos e estilos de vida, aos quais o narrador não orienta sua vontade de sexo. Por isso, seu texto não é sobre uma sociabilidade gay que rasga o discurso oficial sobre a nação, mas sobre um rasgo na própria heteronormatividade nacional.

A nação que Carella descobre é a de homens heterossexuais envolvidos em sexo casual com outros homens, em troca de dinheiro, pequenos trocados, comida, vestuário e, é claro, simplesmente prazer. Heterossexuais porque suas identidades são performadas desta maneira, reiteradas cotidianamente através de práticas normativas como o noivado, o casamento, o trabalho, o comportamento público etc. Não existe perda ou ambiguida- 
de nesses homens, a não ser, é claro, nos homossexuais que o narrador nomeia ao longo do livro, assim identificados porque, por sua vez, performatizam sua homossexualidade ou assim se identificam.

Como a atração de Carella/Ginarte recai em homens pobres, invariavelmente o sexo que fazem possui uma moeda de troca. As exceções expostas pelo texto confirmam a regra: o sexo com marinheiros árabes, que chegam ao Recife e encontram no narrador o indice comum da estrangeiridade; o amigo médico do Rio de Janeiro, que lhe confidencia uma atração sexual, embora não esteja disposto a ceder. Nesses termos, a rasura evidenciada pelos diários de Carella é a de uma nação homossocial.

A homossocialidade diz respeito à dinâmica das relações entre homens, independente de suas identidades sexuais, e ao modo como a masculinidade é exercida e construída. A nação homossocial descrita pelo escritor argentino é um espaço para se pensar além da homossexualidade, pois é sobre a masculinidade oficial que ela versa, ou melhor, sobre os não-ditos dessa masculinidade.

Os matizes existentes no universo de homens que fazem sexo com outros homens são inúmeras; passam do homossexual assumido ao gay no armário, o qual difere de homens que ocasionalmente transam com outros e que, ainda assim, não possuem qualquer identidade homossexual, apenas desejo. E um desejo que não precisa ser exclusivo ou vivenciado numa tortura. Como a experiência de Carella 
deixa claro, não há culpa sob o Sol do Brasil, muito menos pecado. Sobre esses homens, revoa o barulho dos discursos acerca da homossexualidade, da identidade gay, da luta pelos direitos civis dos LGBT e da criminalização da homofobia. Mas em que espectro da sociedade eles estão, se vivem plenamente na heteronormatividade e dela não pretendem sair? A sigla $\mathrm{HSH}$, utilizada oficialmente pelo Ministério da Saúde, por exemplo, coloca a questão em termos mais assépticos do que culturais, embora seja eficiente em não demarcar nenhum tipo de identidade sexual. Como o contexto exposto por Carella é o de homens que se identificam e performatizam a heterossexualidade, a questão permanece problemática.

A sexualidade funciona como um dos vários discursos sobre o nacional, no Brasil. Geralmente apoia-se na sexualidade feminina e na liberalidade de costumes que constituem vários dos discursos pedagógicos da nação, como, por exemplo, o carnaval. O debate sobre isso já avançou muito e assim prossegue, agregando a este discurso a crítica necessária que expõe as contradições de nossa tão falada sensualidade. O fato de o homossexual e sua experiência não se situarem mais no gueto tem sido um item candente da agenda de hoje, ainda que a tática mais conhecida para isso seja a de rearranjar gays e lésbicas, no interior da heteronormatividade, o que resultaria na equivalência discursiva dessas identidades, subtraindo-lhes o potencial desestabilizador da diferença, que permanece forte nos indivíduos transexuais. 
Essa equivalência substitui a ausência de uma proposta homossexual à norma hetero que vingue além do carnaval. É um modo astucioso de adquirir acesso aos direitos civis mais básicos, e atingir tal igualdade que demonstra como a homossexualidade não foi capaz ainda de criar uma alternativa forte à performance heterossexual em que todos os individuos são treinados. A luta por esses direitos, embora seja mais que válida, vai ao encontro da norma em diversos niveis, porque torna homogênea a experiência diversificada de lésbicas, gays e transgêneros. Mesmo as investidas na cultura popular, no cinema e na literatura não têm dado conta, por exemplo, da complexidade identitária de uma lésbica que seja negra, ou de um cross-dresser, ou de quem fez a transição do feminino ao masculino. Já o bissexual permanece nesse quadro como invisível, indeciso ou falso.

Nesta discussão não existe lugar, ainda, para a multidão de homens cuja performance hetero admite o sexo gay, sobretudo porque já estão instalados confortavelmente no interior da heteronormatividade, seja como gays no armário, bissexuais ou admiradores ocasionais (ou não) de sexo homossexual. Estes mesmos homens, contudo, participam como genuínos reiteradores da heterossexualidade e do discurso nacional em suas vidas e vivências. Não têm necessidade de lutar pelo direito do casamento civil, porque já o possuem; não precisam apoiar a criminalização da homofobia, pois não correm o risco de suas performances 
serem confundidas com as de um homossexual; não precisam do conforto de um gueto, pois toda a cidade pode ser sua. Estes homens só têm a preocupação de encontrar o espaço de sociabilidade necessário para a realização de suas práticas, muitas vezes dividindo-o com sujeitos que se identificam como gays.

Os diários que Tulio Carella escreveu no Recife são a história desse indivíduo muito mais astucioso e muito mais adaptado à dinâmica da norma do que seus compatriotas LGBT. Mas a história desses diários também é a desconstrução da identidade masculina heterossexual, seu desejo, sua performatividade e sua legalidade. $O$ texto dilata a ideia de sexo entre homens como forjado pelas necessidades compulsória e monetária ou pela doença, vício e pecado para o campo do mero prazer. Indica que as repetições ritualizadas que nos informam o que é o macho nordestino e o que ele representa se diluem sob a égide do desejo indiscriminado. Seu texto funciona como contradiscurso de uma sexualidade heterossexual que está no cânone da ideia de nação, e da sensualidade brasileira exclusivamente feminina.

A trama que envolve gênero, raça e nacionalidade é intrincada e pouco convidativa a uma análise que não se deixe seduzir pela observação dessas três categorias em separado, mas a experiência vige como relatora de que não se pode pensar como estanques as identidades de gênero e raciais, e mesmo como estas se mesclam na construção do discurso nacional. Avtar Brah (2006, p. 351) 
afirma que "estruturas de classe, racismo, gênero e sexualidade não podem ser tratadas como 'variáveis independentes' porque a opressão de cada uma está inscrita dentro da outra - é constituída pela outra e é constitutiva dela" (grifo do autor).

As indias nuas de Caminha, as imprecações contra sodomitas mulatos feitas por Gregório de Mattos, a mucama Lucinda que perverte sexualmente sua ama, nas Vitimas -algozes, de Macedo, ou as heroínas de Jorge Amado, para citar exemplos que não intentam ser específicos e fechados, são amostras produzidas em solo brasileiro eivadas de implicações entre raça, gênero e classe que contribuiram e ainda retornam fantasmagoricamente para contribuir com a construção de uma nação sensual. O problemático desses discursos simbólicos é que suas leituras tendem, na maioria das vezes, a demonstrar a dificuldade de pensar como um território se transforma em nação, considerando-se, no processo, como as identidades de gênero e de raça, assim como as de classe, foram importantes para a construção desse imaginário.

Como o espaço público é pautado na estrutura da produção e das transformações fixadas por homens, a nação torna-se um discurso masculino e heterossexual, em que mulheres, homossexuais, não-brancos e pobres participam de modo subalternizado. As múltiplas relações de dominação no bojo da colonização, em que todos participaram em determinada escala, possuem pouquíssimo registro que sir- 
va de suporte a uma invectiva contra o status heterossexual da nacionalidade.

Em Orgia, a invectiva, contra o nacional, parte das relações sexuais pouco precisas no plano da identidade, mas bastante acertadas no plano do desejo, entre uma turba de indivíduos homens, heterossexuais, pobres e negros e um estrangeiro. A própria ideia masculina de nação que essa turba representa é cuidadosamente erodida pelo relato do estrangeiro, que corrói sua suposta heterossexualidade radical.

Neste jogo, Carella não consegue fugir da fetichização e de certa ideia tortuosa de colonialismo. $O$ fetiche pela cor negra lhe atiça diariamente a carne, leva-o a uma busca impressionante, de tão obsessiva, por novos homens com quem se deitar. Sua versão do colonialismo (na verdade, seu dom civilizatório) é dar a esses homens a contraparte fetichista, isto é, dar aos negros rudes o refinamento simbólico de sua brancura. Quando um de seus pretendentes revela interesse por teatro, descarta-o com a desculpa de que não quer estabelecer pontes entre esses dois mundos. Os mundos - que o autor não nomeia - são, por um lado, a civilização letrada, que ele oficialmente representa como professor universitário, e o submundo do sexo, em que investe sua energia com bastante determinação. Contudo, a verdadeira ponte desse episódio não seria Carella, mas sim o rapaz interessado em teatro, que representaria o negro com gostos e hábitos mais próximos dos seus, e por isso, sem o fetiche original que o atrai: o fetiche do negro inculto. 
As relações de raça e classe existentes entre homossexuais e homens pobres, que continuam a vivenciar sua heterossexualidade, apesar de às vezes sustentar suas vidas e as de suas mulheres e filhos com dinheiro de amantes gays, são um fenômeno bem conhecido por sociólogos e, inclusive, socialmente aceito nas comunidades mais carentes. Diferindo dos michês, que participam dessa dinâmica na forma de serviço esporadicamente prestado, esses homens mais pobres atuam, com seus amantes homossexuais, num ambiente em que a fetichização também ordena e é tão importante quanto o intercâmbio financeiro. Na prostituição masculina, qualquer ilusão de desejo genuíno é derrubada ao primeiro anúncio do preço dos serviços, enquanto nas relações aqui aludidas supõe-se que o dinheiro seja um facilitador do prazer. Nos diários, isto se manifesta através das intenções do narrador - jamais verbalizadas - de viver com King Kong para mitigar sua solidão e desejo em troca não só de um teto, mas também de algum dinheiro e educação. O que o impede de externar ao parceiro essa vontade, além da desconfiança da recusa, é o receio de viver com um outro tão diferente de si.

Embora muito distinto de homens gays que mantêm relações de concubinato com heterossexuais, Carella trabalha na exposição de uma dupla rasura: a primeira, que diz respeito ao modo como a heterossexualidade, ou como essência masculina ou como caráter nacional, é uma performance reiterada que mostra as 
falhas de sua estratégia em segredo, inclusive deformando o ideal de homem nordestino; a segunda, no papel que negros e mestiços têm no discurso nacional, pois o narrador compreende todo o povo como matizado e não-branco. Por outro lado, seus diários repetem as fórmulas do exotismo tropical, da sensualidade exagerada do brasileiro e de virilidade do homem negro. O fato de serem três lugares-comuns do discurso nacional parece, portanto, corroborar suas impressões.

A ideia de nação é amplamente unificada, entre outros índices, pela heterossexualidade compulsória. Não é apenas como anormais que pessoas gays, lésbicas e trans participam das narrativas nacionais: em determinados âmbitos, essas pessoas sequer existem, ou funcionam como a diferença que justifica a norma. Clamar visibilidade para as narrativas homossexuais como atuantes no processo metafórico nacional talvez não possua o mesmo poder desestabilizador que é questionar, como o texto de Carella permite a própria narrativa oficial da nação no seu estatuto heterossexual. A contranarrativa da heterossexualidade pode ser lida numa chave diferenciada daquela proposta pelos discursos homossexuais na medida em que desloca e questiona o essencialismo sexual em sua forma compulsória. As contranarrativas, diz-nos Bhabha (1998, p. 211),

[...] continuamente evocam e rasuram suas fronteiras desestabilizadoras tanto reais quanto conceituais - perturbam aquelas manobras ideológicas 
através das quais 'comunidades imaginadas' recebem identidades essencialistas (grifo do autor).

A fantasia homoerótica que descreve uma nação como invertida, isto é, com uma heterossexualidade rasurada, impõe-se como reveladora da performance de gênero e, ainda mais do que isso, desarticula a estrutura do discurso nacional de caráter sexual. Essa desarticulação pode ser aproveitada tanto pelas contranarrativas gays, que reivindicam sua participação na metáfora nacional, quanto num reposicionamento do local da heterossexualidade como prática normativa.

Em outras palavras, essa mudança revigora o discurso pós-identitário de gênero como performance ao mesmo tempo em que atua como desconstrução da heterossexualidade nacional. Portanto, em primeiro lugar, isto diz respeito ao questionamento da sexualidade "oficial" como uma invenção cuja narrativa é reiterada num tempo performático, diário; em segundo lugar, essa mudança questiona a representação do "homem nacional", revela os deslocamentos e falhas de sua construção e mesmo joga uma pá de cal na ideia essencialista de heterossexualidade.

Estas contranarrativas também denunciam a maneira pela qual a masculinidade de uma nação é construída a partir da repressão do feminino e do posicionamento público destinado ao homem. Ação entre amigos com identidades e práticas heteronormativas, este 
tipo de sexo homossexual - e anônimo - serve como iteração do papel dominante do homem ou como relaxamento dessa fronteira, quando o macho heterossexual deixa-se penetrar por outro. Para que isto faça sentido, é preciso recorrer ao lugar-comum amplamente reconhecido de que o indivíduo penetrado é um ser passivo numa função subalterna, o que vale tanto para mulheres quanto para homens neste último caso, aliás, ser exclusivamente aquele que se entranha não necessariamente constitui índice de homossexualidade; pelo contrário, é possivel até mesmo compreender isso como expressão de virilidade extrema. Esta lógica do senso comum é quebradiça, apenas substituição e fuga, formulada por uma mentalidade pouco sutil. Carella, que sem dúvida percebia a contradição dessa ideia, assim estabelecida de ser penetrado por outro homem - negro - funciona como fetiche e ritual de dominação: o branco é um deus subjugado pelo negro, que encontra aí o motivo de sua atração.

O discurso erodido da heterossexualidade, contudo, tem no plano diário sua concretude física (e também simbólica) nos espaços de socialização que não podem ser chamados apropriadamente de gays - mas sim de homossociais. Estes espaços contemporâneos - cinemas pornográficos, saunas, cabines de sexo etc. - ainda que sejam frequentados por homens gays fora do armário, têm sua razão de ser na invisibilidade que proporcionam, funcionam ao revés de boates, bares ou festas vendidas sob a 
sigla GLS, que apresentam abertura irrestrita para indivíduos de qualquer orientação sexual, lugar para a presença de mulheres, e territórios de celebração política da visibilidade e afirmação identitária. Como as ruas do Recife de Carella/Ginarte, os espaços para sexo anônimo são locais em que o masculino se reitera, seja pela estrutura relacional exclusivamente masculina, seja pela satisfação do desejo sob o resguardo de fachadas discretas e austeras, em que a identidade hetero apenas momentaneamente se perde. A própria dinâmica é a de uma sociedade secreta, na base do acordo de cavalheiros e do voto de silêncio, com homens reunidos para algumas horas de diversão entre si - a socialização e o sexo vêm confirmar o estatuto masculino oficial.

Estas zonas invisiveis da cidade moderna servem de desafogo da heterossexualidade nacional, que ali deixa aparecer brevemente sua fragilidade conceitual para de novo voltar a recuperá-la no retorno à vida pública. O texto de Carella, que como diário é um produto do imaginário, encontra o mundo e o expõe, mas cede ao ser apropriado como um discurso homossexual e representativo da identidade gay, isto é, perde sua força disruptiva ao mesmo tempo em que apenas se junta à contranarrativa da sexualidade homossexual. Espera-se que a leitura aqui apresentada tenha demonstrado o poder problematizador desse texto em sua contestação da narrativa heterossexual. 


\section{REFERÊNCIAS}

BHABHA, Homi K. O local da cultura. Tradução de Myriam Ávila et al. Belo Horizonte: EdUFMG, 1998.

BRAH, Avtar. Diferença, diversidade, diferenciação. Cadernos Pagu, Campinas, n. 26, p. 329-376, jan.-jun., 2006.

CARELlA, Tulio. Orgia: diário primeiro. São Paulo: Opera Prima, 2011.

SAID. Edward. Orientalismo. Tradução de Rosaura Eichenberg. São Paulo: Companhia das Letras, 2007. 